\title{
Primary T-Cell Lymphoma of the Parotid Gland
}

\author{
Osman Ilkay Ozdamar ${ }^{1}$, Gul Ozbilen Acar ${ }^{1}$, Servet Karaca ${ }^{1}$, M. Tayyar Kalcioglu ${ }^{1}$ and Tulay Zenginkinet ${ }^{2}$ \\ ${ }^{1}$ Department of Otorhinolaryngology, Head and Neck Surgery, Istanbul Medeniyet University, Goztepe Training and Research Hospital, \\ Istanbul, Turkey \\ ${ }^{2}$ Department of Pathology, Istanbul Medeniyet University, Goztepe Training and Research Hospital, Istanbul, Turkey
}

\begin{abstract}
Primary malignant lymphomas of parotid gland are very rare. Most are B-cell lymphomas, and T-cell lymphomas are very rare. Unfortunately, fine needle aspiration biopsy is non-diagnostic. We, herein, present a case of a 51-year male, who presented with a large mass in the left parotid gland that had rapidly grown over a few months. As fine needle aspiration biopsy was non-diagnostic, we decided to take an incisional biopsy to disclose the pathology.

The lesion was diagnosed as T-cell lymphoma after immunohistochemical examination of the specimens. Following 2-[18F] fluoro-2deoxy-D-glucose-positron emission tomography/computed tomography (FDG-PET/CT), the disease was staged as 'Stage I'. The patient received six sessions of cyclophosphamide, doxorubicin, vincristine and prednisone protocol as chemotherapy management. After the completion of chemotherapy, complete remission was achieved.

In suspected cases, an incisional open parotid core biopsy should be considered for a definite diagnosis. As the treatment of lymphomas is not surgical, this approach avoids a parotidectomy, which in turn, avoids facial nerve complications.
\end{abstract}

Key Words: T-cell lymphoma, Parotid gland, Malignant lymphoma, Incisional biopsy, Fine needle aspiration biopsy.

How to cite this article: Ozdamar OI, Acar GO, Karaca S, Kalcioglu MT, Zenginkinet T. Primary T-Cell Lymphoma of the Parotid Gland. J Coll Physicians Surg Pak 2022; 32(03):392-394.

\section{INTRODUCTION}

Primary lymphoma of the parotid gland is an uncommon malignant tumor derived from mucosa-associated lymphoid tissue or an intraglandular lymph node. ${ }^{1}$ The ratio of this malignant disease in salivary glands varies from $1 \%$ to $5 \%$ in different studies. ${ }^{1-4}$ Almost all primary parotid gland malignant lymphomas are of Bcell origin. T-cell originated parotid lymphomas are extremely rare, and no morethan 20 cases have been reported in English literature. $^{2,5}$

The clinical presentation of the disease is usually the painless swelling of the parotid gland, as with other malignant or benign lesions of the gland. However, rapid enlargement of the gland over a few months is the first main symptom, suggesting a malignant tumor; however, moderate enlargement of the gland in this lesion isalso seen. ${ }^{3}$

We, herein, present a case of a primary parotid gland T-cell lymphoma, the first sign being the rapid swelling of the left parotid gland. We discuss this rarely noted malignant disease regarding diagnosis and management with reference to the literature.

Correspondence to: Dr. Osman Ilkay Ozdamar, Department of Otorhinolaryngology, Head and Neck Surgery, Istanbul Medeniyet University, Goztepe Training and Research Hospital, Istanbul, Turkey

E-mail: osmanilkay73@yahoo.com

Received: December 23, 2019; Revised: February 25, 2020;

Accepted: March 09, 2020

DOI: https://doi.org/10.29271/jcpsp.2022.03.392

\section{CASE REPORT}

A 51-year male presented to our clinic with diffuse painless swelling of the left parotid gland, which was occurred over two months back. No enlarged cervical lymph nodes were detected on physical examination. In one month during the completion of patient's examination results, the lesion had grown rapidly.

A fine needle aspiration biopsy (FNAB) of the lesion was non-diagnostic. Ultrasonography (USG) showed an approximately $30 \times 15 \mathrm{~mm}$ hypoechoic cystic lesion with well-demarcated margins and solid component in the left diffusely enlarged parotid gland. Thereafter, a T1- and T2-weighted contrast-enhanced magnetic resonance imaging (MRI) scan disclosed a $38 \times 30 \mathrm{~mm}$ diameter partially cystic mass with the lobulated contours derived from the inferior part of the left parotid gland filling the posterior cervical region and carotid sheath (Figure 1). MRI findings were suggestive of parotid gland-derived malignant tumor or lymphoproliferative disease.

We decided to take an open parotid gland core biopsy from the lesion with an adjacent lymph node excision to avoid delay in diagnosis, and a histopathologic examination was undertaken as soon as possible with the aim of optimising the correct management for the patient. The lesion was diagnosed as Tcell malignant lymphoma after histopathologic evaluation; and the patient was referred to the haematology-oncology clinic in our hospital. On immunohistochemical examination, CD3, CD4, CD5, CD30 and CD43 were positive, and ALK-negative T-cell lymphoma was diagnosed (Figure 2). 
Before treatment planning, with the aim of disease staging, a 2[18F] fluoro-2-deoxy-D-glucose-positron emission tomography/computed tomography (FDG-PET/CT) scan was performed. Following the FDG-PET/CT, the disease was staged as 'Stage I', with the disease localised only to cervical lymph nodes and the left parotid gland.

The patient received six sessions of cyclophosphamide, doxorubicin, vincristine and prednisone (CHOP) protocol as chemotherapy management. Our cancer council decided not to give additional radiotherapy because the disease was not of high grade. After the completion of chemotherapy, complete remission was achieved, verified by FDG-PET/CT, performed three months after treatment. The patient has been free of the disease for nearly three years.

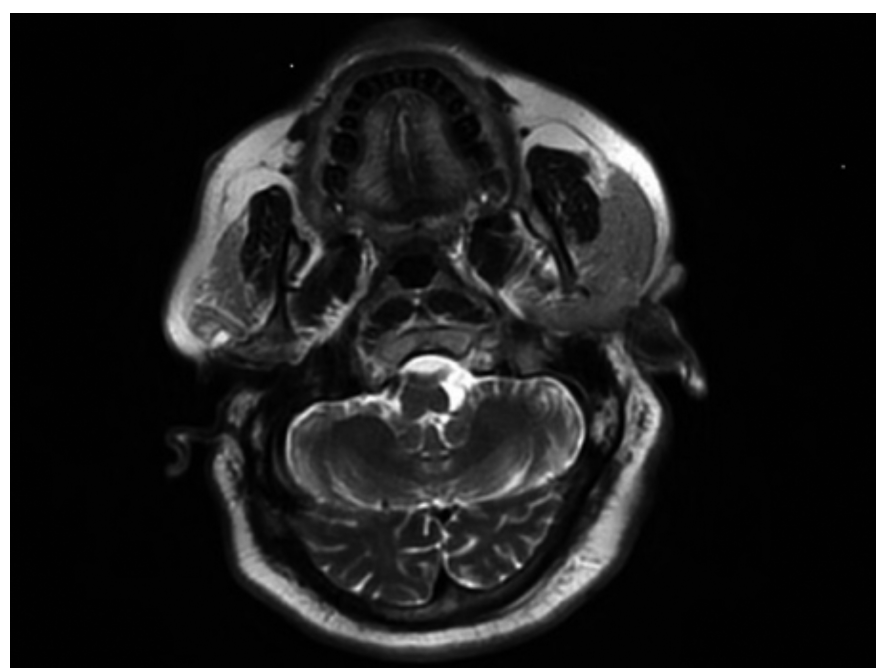

Figure 1: Enlarged left parotid gland is seen on contrast-enhanced T2 weighted MR imaging in axial plane.

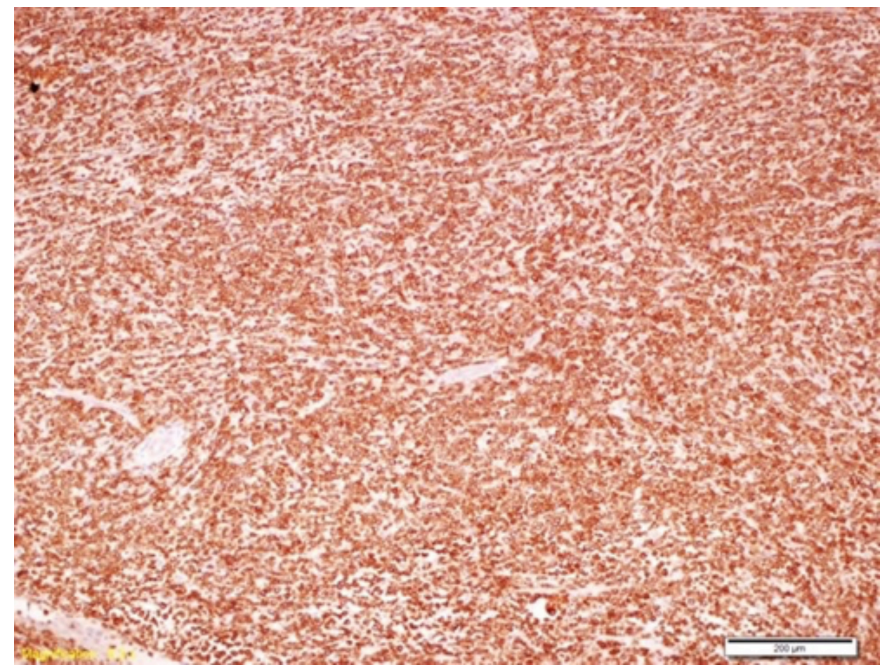

Figure 2: Widespread positive immunoreactivity with CD3, which is specific for T-cells seen with immunohistochemical (IHC) staining (IHC, $\times 100$ ).

\section{DISCUSSION}

Primary lymphoma of the parotid gland presents as the painless swelling indistinguishablefromotherbenignormalignant conditions. Moreover, FNAB and/or frozen sectioning biopsy cannot disclose the correct diagnosis, which, as in ourcase, makes diagnosis difficult. ${ }^{1-5}$

The risk of primary lymphoma of parotid gland increases with age through the $5^{\text {th }}$ to $6^{\text {th }}$ decades of life (average peak is 55 years old). ${ }^{1-3}$ Although the risk for other salivary gland malignancies increases with age, benign tumors have a peak incidence between the $3^{\text {rd }}$ and $5^{\text {th }}$ decades of life. ${ }^{1-4}$ Our patient was 51 yearsold, which was compatible with the literature.

Imaging methods, such as MRI, CT and USG, have limited value in the diagnosis of the disease. However, Hyman and Wolff suggested criteria for considering a malignant lymphoma as having a primary parotid gland origin. ${ }^{6}$ Our case matched with those criteria; the first clinical manifestation of the disease was glandular involvement, which was painless diffuse swelling of the parotid gland, and involvement of the glandular parenchyma with the malignant nature of the T-cell lymphoma.

The management of this malignant disease with chemotherapy \pm radiotherapy independent of preceding surgical management is very satisfactory for those with 'Stage $\mathrm{I}^{2-5}$, as was our case.

In conclusion, primary parotid gland T-cell lymphoma, although very rare, should be kept in mind in the differential diagnosis of parotid gland masses. The most striking clinical and diagnostic finding for suspected primary parotid gland lymphoma is a diffuse, rapid and painless swelling of the parotid gland over a few months without well-defined mass margins on palpation. The detection of the disease with an open core parotid biopsy and adjacent lymph node excision protects patients from surgery-related complications, mainly facial nerve injury.

\section{CONFLICT OF INTEREST:}

The authors declared no conflict of interest.

\section{AUTHORS' CONTRIBUTION:}

OIO: Substantial contribution to the conception and design of the work and interpretation of data for the work.

GOA: Substantial contribution to the conception and interpretation of data for the work, drafting the work or revising it critically for important intellectual content.

SK: Interpretation of data for the work, drafting the work, final approval of the version to be published.

MTK: Substantial contributions to the conception and design of the work.

TZ: Design of the work and interpretation of data for the work.

\section{REFERENCES}

1. Yaprak N, Temel IC, Derin AT, Güney K. Diagnosis and treatment of malignant lymphomas of parotid gland. Kulak Burun Bogaz Ihtis Derg 2015; 25(6):346-9. doi: 10.5606/ kbbihtisas.2015.98254.

2. Onec B, Koc A, Unlu EN, Ünlü I, Yaman H, Köş DM. T-cell lymphoma presenting with auricular and parotid gland involvement. Turk J Haematol 2016; 33(1):75-6. doi: 10.4274/tjh.2015.0217.

3. Hirokawa N, Hareyama M, Akiba H, Satoh M, Oouchia A, 
Tamakawa $\mathrm{M}$, et al. Diagnosis and treatment of malignant lymphoma of the parotid gland. Jpn J Clin Oncol 1998; 28(4):245-9. doi: 10.1093/jjco/28.4.245.

4. Lieder A, Franzen A. Management of primary malignant lymphoma of the parotid gland in a series of 745 patients. Clin Otolaryngol 2017; 42(2):477-80.
5. Dispenza F, Cicero G, Mortellaro G, Marchese D, Kulamarva G, Dispenza C. Primary non-Hodgkins lymphoma of the parotid gland. Braz J Otorhinolaryngol 2011; 77(5):639-44. doi: 10.1590/s1808-86942011000500017.

6. Hyman GA, Wolff M. Malignant lymphomas of the salivary glands. Am J Clin Pathol 1976; 65(4):421-38. doi.org/10. 1093/ajcp/65.4.421. 